\title{
FLUID POWER SYSTEMS ON HYDRAULIC EXCAVATORS
}

\author{
Shuji Hori, Kazunori Ikei \\ Component Technical Center Komatsu Ltd. \\ 400 Yokokura-Shinden 、Oyama-shi、Tochigi-ken、323 Japan
}

\begin{abstract}
CLSS (Closed-Center-type Load Sensing Systems) for fluid power controls in hydraulic excavators are capable of controlling complex motions of multiple actuators with high accuracy against varying loads under varying engine speed conditions, with expectations for improved controllability and compatibility of hydraulic excavators to many kinds of works in which attachments are used. Conversely, operators have made the best use of the characteristics of conventional fluid power systems, in which each actuator speed is varied by inertia or engine speed change.

Accordingly in 1993, a range of new hydraulic excavators were introduced, equipped with newly developed CLSS's, which are suitable for either traditional excavator use or new electrical operation, including automatic electronic control by microcomputer.
\end{abstract}

\section{KEY WORD}

Closed-Center 、Load Sensing 、CLSS 、 hydraulic excavators

\section{INTRODUCTION}

With CLSS (Closed-Center-type Load Sensing Systems) we can control the speed of more than two actuators free from their load by controlling the stroke of each valve. This characteristic of CLSS will reduce the operational difficulties of hydraulic excavators (Fig.1) remarkably and will enlarge the acceptability's of many kinds of working attachments (1)(2). Besides the flow control function, the flow distributing function is necessary to apply CLSS

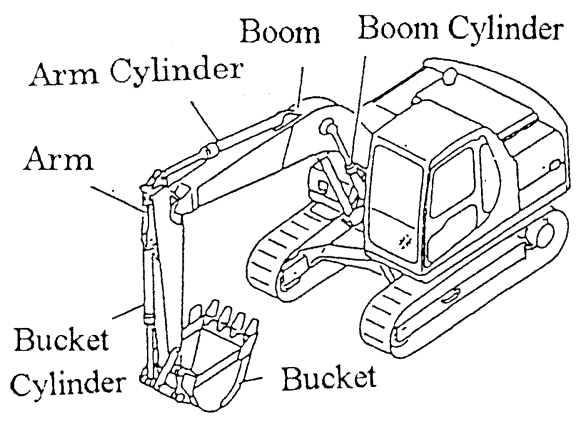

Fig.1 A Typical Hydraulic Excavator 
for hydraulic excavators $(3)(4)$. On hydraulic excavators, working attachments are operated freely by controlling their ultiple actuator speed independently. That means priorities can not be set among each of the actuators. On the other hand the actuators of hydraulic excavators are often operated simultaneously under insufficient flow rate. In that case the metering pressure differences can not be kept at the constant values for one operating actuator.

Therefore in a system of multiple actuators such as a hydraulic system on excavators, the flow rate does not need to be directly proportional to the spool stroke but (instead of the flow rate) flow distribution rate is necessaring to be proportional to the rate of stroke of each spool. In such cases the metering pressure differences are not necessary to be kept at a predetermined value but are at the same value for each spool. We will refer to this type of pressure compensation as flow dividing type pressure compensation $(5)(6)(7)$. For this, pressure compensators up stream of the metering orifices have an advantage $(9)$.

The important application point is that the proper design must have a function for equalizing the metering pressure differences. That means no matter which side of the metering orifices pressure compensators are equipped.

With these improvements, CLSS could be applied to the hydraulic excavators and were adopted to some European and U.S. excavators $(8)$. But there were some problems still remaining.

\section{PROBLEMS OF STATIC CHARACTERISTICS AND ADDITIONAL FUNCTIONS}

\section{(2-1) SPEED REDUCTION}

[ Flow reduction is sometimes necessary. ]

In the case when constant actuator speed is necessary independent of engine speed such as drum driving on cement mixers or generator driving on aircraft, the constant metering pressure difference is convenient. On the other hand, actuator speed is reduced proportional to engine speed on excavators up to present. It has been convenient for excavators to have proportional actuator/engine speed reduction because operators could use such machines with reduced engine speed for easier fine operations. European excavators equipped to CLSS system have sometimes compensated this problem by adding an extra pump for swing motor operation. It enables the swing speed to be reduced proportionally with engine speed (independent swing system). But this independent swing system has proven inefficient with less working capability so now they are eliminated from the market because of new consumer demand.
To accommodate a CLSS system with only one pump, it is necessary to add a system which reduces swing speed proportional to engine speed. This is achieved by reducing metering pressure difference with decreasing engine speed. Different from independent swing system, control gain (flow rate / spool stroke) is reduced at the lower engine speed and it achieves easier fine control not only for swing operation but also for boom and arm operation for fine finishing. It makes possible to set the metering pressure difference at a smaller value even at the higher engine speed via a mode push button for " fine control mode ".

\section{(2-2) SWING AND BOOM LIFT}

[ Flow control and flow dividing are not always necessary. ]

When loading to dump trucks, the excavator boom is lifted and the swing is accelerated simultaneously. The most efficient way to use the engine power in this movement is to provide oil from one pump to a parallel connected boom cylinder and motor (uncompensated parallel system). With this system the swing motor is accelerated by the lifting load of the boom cylinder. In this case, flow dividing pressure compensation is inconvenient. If pressure compensation is chosen, the following disadvantages exist.

At first, the exact flow dividing even for the large inertia load provides wasted divided flow from safety valve at the beginning of the acceleration. It results in a temperature rise of the oil and reduces boom lifting speed. However with an uncompensated parallel system, all the flow rate is provided to the smaller inertia load (boom) at the beginning of the acceleration, and the power loss is minimized. (At the acceleration, the speed of large inertia load is zero and that of smaller inertia load becomes immediately maximum. Then the large inertia is accelerated gradually and smaller inertia load loses its speed. This behavior is especially convenient for excavators and this is one of the reason why Japanese manufacturers have not adopted independent swing systems. )

Secondly, the pressure compensator at the lower loaded actuator (boom) decreases its opening area, raising the pump discharge pressure more than the set value of safety valve at the large inertia load. This causes the unnecessary rise of oil temperature and power loss. The uncompensated parallel system doesn't reduce any open area at the circuit thereby eliminating any losses. At the simultaneous operation on hydraulic excavators, we some times do not need accurate load sensing.

A final point is that hydraulic excavators with variable displacement pumps usually have a power constant control for better matching of engine and hydraulic power. The pump discharge flow rate at 
swing safety valve set pressure is lower than that of the boom lifting pressure. This means the system with pressure compensators provides less flow rate to the actuators.

From these three points it can be seen that flow dividing pressure compensation causes less boom lifting speed and worse efficiency, especially when the dump trucks are waiting at 90 degrees from the digging point (90 degrees swing), and it needs more boom lifting height than the 180 degrees swing. To avoid this condition, the swing pressure sensing circuit is disconnected when the boom lifting lever is operated.

\section{(2-3) LOAD INTERFERENCE}

[ Skilled operators sometimes take advantages of load interference. ]

When fine finishing at a rice field, the tip of the bucket is operated horizontally. In this movement, after the arm is stretched and the bucket is put at the ground, the arm is then curled and boom is lifted simultaneously. Then the boom lever is controlled delicately along as the arm position changes. For high accuracy of finishing surface, the arm actuator speed must be proportional to the arm lever stroke and must be independent of the boom speed especially for unskilled operators (interference free).

But on the other hand for speedy operation of working attachments, it is desirable to utilize the whole pump discharge regardless of the arm position change. And also when the bucket hits on especially hard rock during digging, the interference makes the arm speed decrease and the boom speed increase. This makes the bucket tip away from the higher load and the bucket will not stop. This makes the operators feel the machine's power and skillful operators sometimes use this behavior.

Accurate pressure compensation, which prevents load interference provide easier operation for most of operators including unskilled operators, but it is sometimes unsatisfactory for skilled operators. It is solved by making compensation inaccurate. That means when the pressure of one actuator becomes less than the other actuators, the flow rate to this lower loaded actuator increases a little. This actual value of "a little" depends on the machine size, working attachments and moving directions, and is decided by each manufacturer's own designing preference.

One way to reduce the pressure compensation is to have less load sensing sectional area of the pressure compensators. The second way is to have some pressure drop of the load sensing circuit up stream of the compensators. The third way is to reduce the pressure compensator set value with the pressure rising down stream of the compensators.
3. PROBLEM OF

\section{DYNAMIC CHARACTERISTICS ADDITIONAL FUNCTIONS}

\section{(3-1) MOMENTARY DROP AND \\ PRESSURE COMPENSATION}

The highest loaded pressure signal should be communicated through the load sensing line. Direct connection from the actuator to the load sensing line through the shuttle valves were traditionally used. With this system, when the attachment is raised again after maintening a load, the oil flow from the pressurized side of the boom cylinder to the load sensing line allows the attachment to drop momentarily. Or this movement with slow swing driving simultaneously, makes the boom cylinder pressurized oil to flow through the shuttle valves to the swing motor and accelerates it.

To prevent these unintended movements, the load sensing line should not be communicated from the actuator circuit directly. The solution was derived in the following manner. Sensing lines are connected from the pump delivery circuit, and when the actuator driving pressure is lower than that of pump discharge, pressure drop is generated between pump discharge and load sensing line (Middle pressure sensing, or pressure reducing valve). With this system the above mentioned problems are eliminated. Further more with this system the load sensing pressure never exceeds pump discharge pressure even when the actuator pressure is higher than pump discharge pressure. This causes pressure compensation modulation during actuator start-up.

\section{(3-2) CAVITATION PREVENTING AT RAPID} STOPPING OF LARGE INERTIA

[Pump minimum discharge flow rate may not be zero even with closed-center type control valves. ]

Inertia of upper revolving structures on hydraulic excavators are large. When rapid stopping of their motion, the flow rate return from swing motor through the safety valve is inadequate to prevent cavitation. With an open center type control valve system back pressure is generated by the return flow from pump to tank even at the neutral position. This makes the suction flow to the swing motor. CLSS with closed center type control valves makes it possible to set the pump minimum discharge at zero, but it causes cavitation during the swing stop operation. Setting the pump minimum flow at the same amount as that of conventional system and letting the flow return to the reservoir through an unloading valve to generate back pressure, prevents cavitation of swing motor.

\section{SUMMARY}

Adopting CLSS brings the remarkable progress of 
controllability and suitability for attachments. But until now machine designers and operators were applying and utilizing conventional systems. That was plagued with many difficulties. Therefore, to adopt CLSS without system forethought will be dangerous. By analyzing each operation and attachment movement and it is decided if the feature of CLSS is suitable to those operations. An excavator can be provided that functions with both features are averaged or individual strengths selected.

From the above mentioned improvement a hydraulic excavator with CLSS provided high controllability and high suitability for attachments without losing any features of conventional machines. Moreover the less drift of attachment movement from operation signal makes it easier to control machines by electronics or automatic controls .
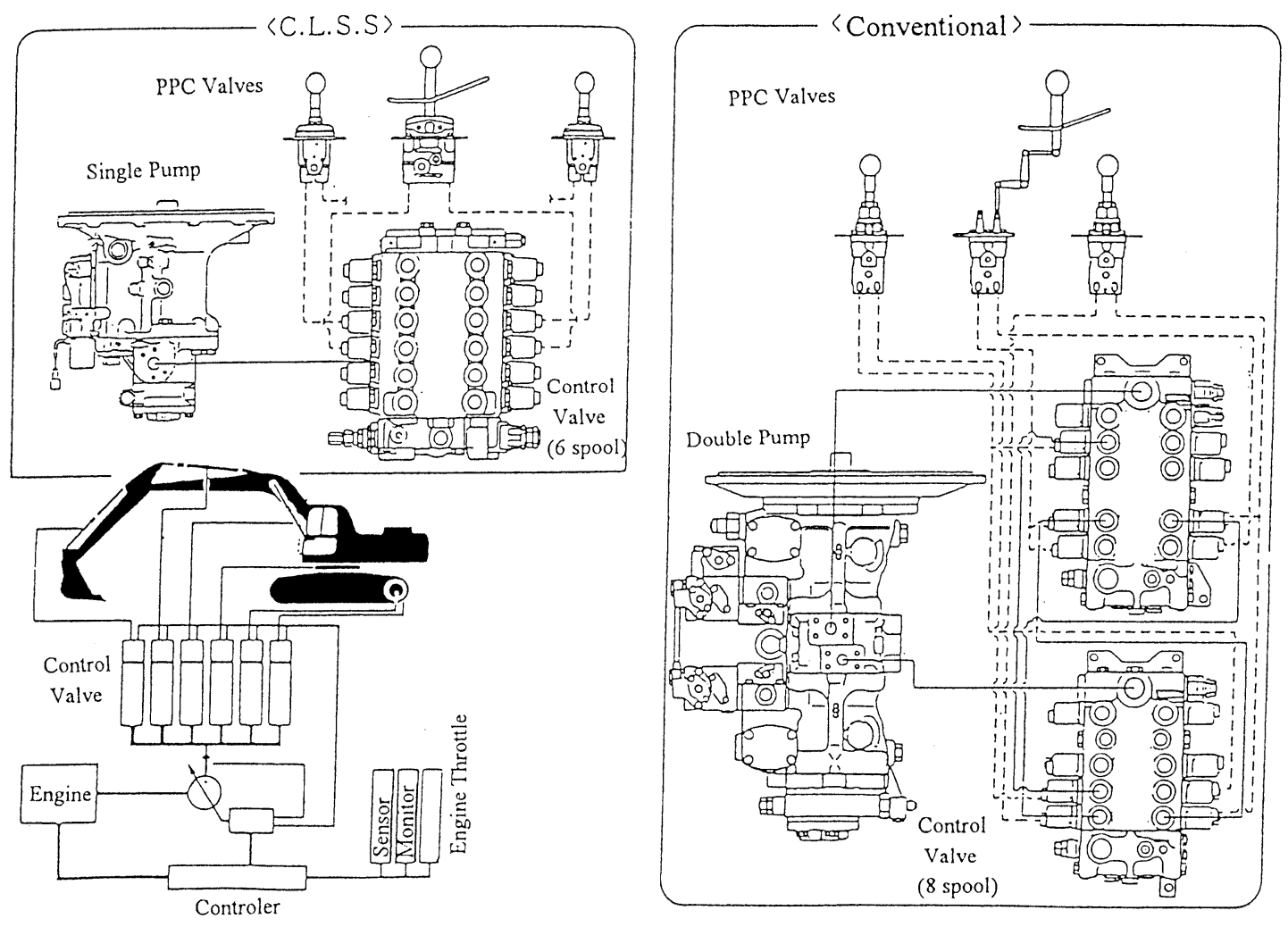

fig. 2 C L S S \& Conventional System

\section{REFERENCES}

(1) W.T.Stephens and H.N. Underwood " New Concept in Hydraulic Controls for Mobile Equipment " Paper 650669, SAE Meeting, Milwaukee, Sept. 1965

(2) A. Myers " Controlling Variable Displacement Hydraulic Pumps for Energy Conservation " Paper 750807 , SAE Meeting, Milwaukee, Sept. 1975

(3) B.Lanto, J.O.Palmberg and P. Kurs " Static and Dynamic Performance of Mobile Load-Sensing Systems with Two Different Types of Pressure Compensated Valves " Paper 901552, SAE Meeting, Milwaukee, Sept. 1990 (4) Y.Aoki, K.Uehara, T.Karakama, K.Morita, T.Akiyama, Y.Oda " Load Sensing Fluid Power System " Paper 941714, SAE Meeting, Milwaukee, Sept. 1994

(5) T. J. Malott and J. C. Paul ; U.S.P. 3,827,453 Patented Aug. 6, 1974

(6) W. Zirps Deutsches Patentamt Offenlegungsschrift 2906670 (4. 9. 80)

(7) R. A. Wilke ; U.S.P. 4,693,272 Patented Sept. 15, 1987

(8) S. H. Johnson and L. L. Williams ; E.P.A. 0,279,356 Nov. 2, 1988

(9) K. Shirai, K. Uehara, K. Morita, T. Takiguchi and N. Ishizaki; U.S.P. 5,188,147 Patented Feb. 23, 1993 